\title{
AMPLIANDO OLHARES E PRÁTICAS: ESCUTA ÀS MULHERES ATENDIDAS EM UM CENTRO DE PARTO NORMAL
}

\section{BROADENING GLANCES AND PRACTICES: LISTENING TO WOMEN ATTENDED AT A NATURAL BIRTH CENTER}

\section{AMPLIANDO LAS MIRADAS Y PRÁCTICAS: ESCUCHANDO A LAS MUJERES ASISTIDAS EN UN CENTRO DE PARTO NORMAL}

\section{Maria Rafaela Amorim de Araujo ${ }^{1}$, Fernanda Celiberti Soveral Pelizzoli², Viviane Maria Gomes de Araújo ${ }^{3}$}

Fontes de financiamento: Capital próprio.

Vinculação do manuscrito: Trabalho de Conclusão de Residência em Enfermagem Obstétrica do Instituto de Medicina Integral Professor Fernando Figueira (IMIP).

Como citar esse artigo: Araujo MRA, Pelizzoli FCS, Araújo VM. Ampliando olhares e práticas: escuta às mulheres atendidas em um centro de parto normal. Rev Enferm Atenção Saúde [Internet]. 2021 [acesso em:__]; 10(3):e202130. doi: https://doi.org/ 10.18554/reas.v10i3.4649

\section{RESUMO}

Objetivo: Analisar a percepção das mulheres sobre a assistência que receberam no Centro de Parto Normal do Instituto de Medicina Integral Professor Fernando Figueira. Método: Tratase de uma pesquisa descritiva e exploratória, com abordagem qualitativa. Realizada em um Centro de Parto Normal do Recife - Pernambuco, com 18 puérperas. Utilizou-se a técnica de observação participante e entrevistas semiestruturadas, analisadas a partir da técnica de análise de conteúdo. Resultados: Observou-se um espaço saudável e acolhedor, com direito a acompanhante durante todo o período. A maioria dos partos ocorreu sem nenhuma intervenção, com destaque para os métodos não farmacológicos de alívio da dor. No período após o nascimento foi relatado o respeito à 'hora dourada', no sentido de minimizar a separação entre mãe e bebê. Conclusão: A satisfação com a assistência de enfermagem foi o sentimento que predominou, os cuidados técnicos e humanos seguem as boas práticas de atenção ao parto.

Descritores: Serviços de Saúde Materno-Infantil; Parto Humanizado; Satisfação do Paciente; Enfermeiras Obstétricas.

\footnotetext{
${ }^{1}$ Enfermeira pela Universidade de Pernambuco (UPE). Mestranda em Saúde Pública pela Fundação Oswaldo Cruz Pernambuco (Fiocruz PE) - Instituto Aggeu Magalhães (IAM). http://orcid.org/0000-0002-9565-6285. E-mail: rafaelaamorim.enf@gmail.com

${ }^{2}$ Enfermeira pelo Centro Universitário Maurício de Nassau - Recife (UNINASSAU). Mestre em Saúde Pública pela Fundação Oswaldo Cruz Pernambuco (Fiocruz PE) - Instituto Aggeu Magalhães (IAM). http://orcid.org/0000-0002-1412-806X

${ }^{3}$ Enfermeira pela Universidade de Pernambuco (UPE). Mestre em Hebiatria pela UPE. http://orcid.org/0000-00029195-4074
} 


\section{ABSTRACT}

Objective: To analyze the perception of women who received assistance at the Normal Birth Center of the Professor Fernando Figueira Institute of Integral Medicine. Method: It followed a descriptive exploratory design, of qualitative approach. Accomplished at Normal Birth Center, located in the city of Recife - PE, with 18 postpartum women. The participant observation technique was used and semi-structured interviews, analyzed using the content analysis technique. Results: A healthy and welcoming space was observed, entitled to companion throughout the period. The most births occurred without any intervention, especially non-pharmacological pain relief methods. In the period after birth, respect for the 'golden hour' was reported, in order to minimize the separation between mother and baby. Conclusion: The satisfaction with the care received was the predominant feeling, technical and human care follow the good practices of childbirth care.

Descriptors: Maternal-Child Health Services; Humanizing delivery; Patient Satisfaction; Nurse Midwives.

\section{RESUMEN}

Objetivo: Analizar la percepción que tienen las mujeres sobre la asistencia que recibieron en el Centro de Parto Normal del Instituto de Medicina Integral Profesor Fernando Figueira. Método: Investigación descriptiva y exploratoria, con un enfoque cualitativo. Realizada en un Centro de Parto Normal en Recife - Pernambuco, con 18 puérperas. Se utilizó la técnica de observación participante y entrevistas semiestructuradas, analizadas a partir de la técnica de análisis de contenido. Resultados: Se observó un espacio saludable y acogedor, con derecho a un acompañante durante todo el período. La mayoría de los partos ocurrieron sin ninguna intervención, priorizando los métodos no farmacológicos para aliviar el dolor. En el período posterior al nacimiento, se informó el respeto por la 'hora dorada', para minimizar la separación entre la madre y el bebé. Conclusión: Predominó la satisfacción con la atención de enfermería, los cuidados técnicos y humanos siguen las buenas prácticas para la atención al parto.

Descriptores: Servicios de Salud Materno Infantil; Parto Humanizado; Satisfacción del Paciente; Enfermeras Obstetras.

\section{INTRODUÇÃO}

O deslocamento do cuidado feminino pelo poder médico e a institucionalização do parto nos hospitais, inscreveu a gestação na lógica da patologia, houve uma supervalorização dos riscos e uma subestimação da capacidade da mulher em parir sem necessitar de todo o aparato tecnológico. ${ }^{1-2}$ Além disso, a mulher passou a ser desconsiderada como sujeito ativo e consciente, livre para gestar e parir de acordo com seus desejos, colaborando para as relações de dominação de gênero. ${ }^{1}$

Em meados da década de 80 , com a expansão dos grupos feministas, o tema da saúde da mulher conquista espaço e importância no Brasil. $^{2}$ Diante de um contexto fortemente marcado pela chamada epidemia de cesáreas, desenvolveu-se a compreensão do parto como tema integrante da agenda dos direitos reprodutivos, o movimento feminista denunciava a violência obstétrica 
e a ausência de protagonismo feminino. ${ }^{1}$ Houve uma aproximação da abordagem humanizada, lutando pela revalorização das dimensões sexuais, sociais e espirituais do nascimento. ${ }^{2}$

O Ministério da Saúde (MS), a partir da década de 90, publicou portarias em prol da humanização da assistência ao parto. Em 1999, instituiu o Centro de Parto Normal (CPN) no âmbito do Sistema Único de Saúde (SUS), e em 2015 redefiniu as diretrizes para sua implantação e habilitação em conformidade com o componente 'parto e nascimento' da Rede Cegonha. Inserido nessa rede de cuidados, o CPN objetiva promover a humanização e a qualidade do atendimento à mulher na assistência ao parto normal sem distocia, que pode funcionar fisicamente integrado ou isolado do hospital, e que enfermeiras obstetras compõem a equipe mínima. ${ }^{3}$

Apesar do CPN ter sido criado há mais de vinte anos, existe um número reduzido de unidades no Brasil, talvez reflexo da hegemonia do parto medicalizado e hospitalar, além dos conflitos decorrentes da divisão técnica e social. ${ }^{4}$ A assistência neste local considera o parto um processo fisiológico e as enfermeiras obstetras estão entre as profissionais mais adequadas para o seu acompanhamento, contribuindo para a sua evolução natural pelas características menos intervencionistas dos cuidados. ${ }^{5} \mathrm{~A}$ assistência de qualidade à mulher em trabalho de parto é um direito fundamental e representa um passo indispensável para garantir que ela possa exercer uma maternidade voluntária, prazerosa, segura e socialmente amparada. ${ }^{2}$

Entretanto, há uma escassez de dados sobre a qualidade da assistência nos CPN, segundo a perspectiva das mulheres atendidas. ${ }^{4}$ A percepção das usuárias reflete os diversos momentos da assistência, bem como a maneira como os cuidados são dispensados ou recebidos. Desta forma, conhecer por meio das usuárias a realidade desse modelo de atenção obstétrica em uma instituição do nordeste brasileiro, possibilita a ampliação de uma estratégia de cuidado mais respeitosa e humanizada. Diante disso, a pergunta norteadora deste estudo foi: 'Qual a percepção das mulheres sobre a assistência que receberam no $\mathrm{CPN}$ do Instituto de Medicina Integral Professor Fernando Figueira (IMIP)?'. O objetivo foi analisar a percepção das mulheres sobre a assistência que receberam no $\mathrm{CPN}$ do IMIP.

\section{MÉTODOS}

Trata-se de um estudo descritivo e exploratório, com abordagem qualitativa, o qual se aprofunda no mundo dos significados das ações e relações humanas, fenômenos que não podem ser reduzidos a 
equações, médias e estatísticas. ${ }^{6} \mathrm{O}$ cenário foi o IMIP, localizado na cidade do Recife - PE, uma instituição filantrópica vinculada ao SUS e que tem tradição no atendimento da gestante de alto risco. Mais especificamente, a pesquisa foi desenvolvida no CPN, reformulado em um novo espaço no mês de julho de 2018 para atender as mulheres de risco habitual. Classificado como tipo II, por estar localizado nas dependências internas do estabelecimento hospitalar, conta com cinco leitos e atende o pré-parto, parto e pós-parto (PPP). ${ }^{3}$ A assistência é desenvolvida no local por uma equipe composta por enfermeiras obstétricas e técnicas de enfermagem.

A população do estudo foram mulheres no puerpério imediato, atendidas no CPN do IMIP durante o trabalho de parto e parto, e com idade maior ou igual a 18 anos. Foram excluídas as mulheres que tiveram alguma complicação no parto e necessitaram de maiores cuidados. A amostra foi aleatória, delimitada pelo critério de saturação dos dados, definido como a suspensão de inclusão de novas participantes quando os dados obtidos passam a apresentar, na avaliação das pesquisadoras, certa redundância ou repetição. ${ }^{7}$ A partir disso, foram selecionadas 18 participantes.

A coleta de dados foi realizada em fevereiro de 2019, por meio de observação participante com registro em diário de campo e de entrevistas semiestruturadas com gravação de áudio. Como citado anteriormente, a pergunta norteadora foi: 'Qual a percepção das mulheres sobre a assistência que receberam no CPN do IMIP?'. Os temas investigados incluíram: acolhimento pela instituição, percepção do espaço físico, permissão de acompanhante, tratamento recebido pelos profissionais, procedimentos realizados e satisfação com a assistência. As entrevistas foram realizadas dentro das primeiras 48 horas após o parto, no quarto privativo em que a paciente se encontrava acomodada.

Depois de transcritas, as entrevistas foram submetidas a análise de conteúdo proposta por Bardin, que equivale a um conjunto de técnicas de análise das comunicações e organiza-se em torno de três polos cronológicos: 1) a pré-análise, onde foi realizada a chamada leitura 'flutuante'; 2) a codificação, que é o processo pelo qual os dados brutos são transformados; 3) o tratamento dos resultados, etapa na qual também acontece a interpretação dos dados. ${ }^{8}$ A partir dessa análise, emergiram três categorias, elaboradas pelo critério de relevância com base no objetivo e na literatura científica orientadora do estudo.

Ressalta-se que a coleta de dados, foi iniciada somente após aprovação pelo Comitê de Ética em Pesquisa do IMIP, 
parecer 3.077.874; observando-se as recomendações da Resolução n ${ }^{\circ}$ 466/2012 do Conselho Nacional de Saúde (CNS), que trata de pesquisas envolvendo seres humanos. 9 Todas as participantes, após receberem as devidas informações pertinentes ao estudo juntamente com o Termo de Consentimento Livre e Esclarecido (TCLE), aceitaram, voluntariamente, participar da entrevista. Visando o anonimato e em homenagem à Dona Prazeres (enfermeira e parteira, Patrimônio Vivo de Pernambuco), as participantes foram codificadas pelo nome

'Prazeres', seguido de um número para representar a ordem de participação.

\section{RESULTADOS E DISCUSSÃO}

O perfil das 18 mulheres, que participaram do estudo, está detalhado na Tabela 1. A idade variou de 19 a 35 anos, com uma média de 25 anos (desvio padrão $\pm 4,9$ ). A maioria autodeclarou raça/cor parda $(88,9 \%)$, possuía ensino médio completo $(38,9 \%)$ e era dona de casa $(66,7 \%)$ (Tabela 1). Além disso, a média de paridade foi de dois filhos (desvio padrão \pm 1 ) e quatro mulheres eram primíparas.

Tabela 1. Características sociodemográficas de puérperas atendidas no Centro de Parto Normal, do Instituto de Medicina Integral Professor Fernando Figueira. Recife, 2021.

\begin{tabular}{lcc}
\multicolumn{1}{c}{ Características } & N & \% \\
\hline Raça/cor & 16 & 88,9 \\
Parda & 02 & 11,1 \\
Branca & & \\
Situação conjugal & 15 & 83,3 \\
União estável & 02 & 11,1 \\
Casada & 01 & 5,6 \\
Solteira & & \\
Escolaridade (nível) & 05 & 27,7 \\
Fundamental incompleto & 04 & 22,2 \\
Médio incompleto & 07 & 38,9 \\
Médio completo & 01 & 5,6 \\
Superior incompleto & 01 & 5,6 \\
Pós-graduação completa & & \\
Ocupação & 12 & 66,7 \\
Dona de casa & 01 & 5,6 \\
Analista de tecnologia da informação & 01 & 5,6 \\
Autônoma & 01 & 5,6 \\
Balconista & 01 & 5,6 \\
Cabelereira & 01 & 5,6 \\
Estudante & 01 & 5,6 \\
Vendedora de peixe & &
\end{tabular}

Fonte: Elaboração própria, 2021.

\section{Boas práticas durante o trabalho de parto e parto}

Ao ser internada a gestante é encaminhada ao CPN e o primeiro aspecto que chama atenção é a ambiência, que representa um espaço planejado de acordo com as necessidades das usuárias e 
trabalhadoras - saudável, acolhedor e confortável. ${ }^{10}$ São cinco suítes privativas, com nome de flores para identificá-las, têm quarto PPP e banheiro com chuveiro quente, sendo que uma também conta com banheira. Todas as mulheres entrevistadas avaliaram o local como ideal para vivenciar a experiência do parto e nascimento, observaram-se fatores como higiene, silêncio e privacidade. Narrado do seguinte modo:

Achei bom, eu pensei que ia ser uma sala cheia de gente, aquela agonia toda que a gente ver né, mas foi bom (Prazeres 9).

Eu tava me sentindo confiante até pelo ambiente que eu tava [...] Tudo limpo, tudo tranquilo, tudo bem organizado, não tem nada deixado de lado (Prazeres 1).

Eu tive privacidade em tudo, porque tudo eles avisa, pede licença, eu me senti bem, bem mesmo (Prazeres 18).

O espaço adequado também favorece a política interna que permite, durante o trabalho de parto e parto, a presença de dois acompanhantes de livre escolha da paciente e mais uma doula. As escolhas das participantes com relação a seus acompanhantes variaram entre a mãe, a sogra, as amigas e o companheiro. Os benefícios reconhecidos foram principalmente no aspecto emocional, que favorece o conforto e encorajamento da mulher, minimizando ansiedade e estresse, um estudo realizado em um CPN do Piauí apresentou achados semelhantes. ${ }^{11}$
Ah quando a pessoa tem uma pessoa conhecida da pessoa né, a pessoa assim sofre, mas sabendo que tem aquela pessoa né do lado ajudando (Prazeres 13).

Eu recomendo fortemente uma doula pra todo mundo, porque como você não conhece muito o processo, tinha hora que você tava tão cansada que você já achava que não aguentava mais sabe e ela deu um apoio moral e físico, muito pra mim e pro meu marido também (Prazeres 12).

Como destacado na fala acima, além do seu esposo como acompanhante, uma parturiente teve a assistência de uma doula particular. Única a experimentar esse cuidado específico, visto que a maternidade não dispõe de um programa de doulas voluntárias. A doula é considerada uma mulher com conhecimento e destreza para promover suporte físico (massagem, exercícios, auxílio na respiração) e emocional (acalmar, encorajar, dar suporte informativo). Essa parceria no cuidado pode aumentar a satisfação da paciente, por isso é necessário avançar com a discussão para que o papel da doula seja reconhecido e validado. ${ }^{12}$

O apoio por pessoal de fora da equipe hospitalar não dispensa o apoio oferecido pelas enfermeiras. As recomendações enfatizam, além do apoio, os métodos não invasivos e não farmacológicos de alívio da dor do parto. ${ }^{13}$ Observou-se entre as principais práticas: massagem, banho de aspersão e 
aromaterapia. Além, de serem encorajadas a se movimentar e adotar posições mais verticais que lhes eram confortáveis, como colocam as mulheres:

A enfermeira deu massagem em mim, banho quente eu tomei [...] (Prazeres 4).

Eu caminhei, fui pra bola, fiz exercício no negócio que tem ali, agachamento (Prazeres 7).

Mostraram a posição melhor pra o bebê descer, pra mim também, foi ótimo (Prazeres 14).

As posturas verticais e a mobilidade materna, durante o primeiro estágio do trabalho de parto, podem melhorar o progresso do trabalho de parto e promover melhores resultados maternos e neonatais. ${ }^{14}$ Em vista disso, as gestantes devem ter acesso a informações baseadas em evidências, para estimular sua autonomia nas tomadas de decisão. Como no relato a seguir, mesmo quando elas optam por ficar no leito, devem ser respeitadas:

Tive minha liberdade de ficar na posição que eu queria, que elas deixou eu deitada. Elas não fez assim 'você tem que se levantar pra andar, sentar na bola'. Eu fiquei deitadinha e elas deixaram (Prazeres 15).

Igualmente, foi considerado o desejo das parturientes de comer e beber durante o trabalho de parto, Prazeres 6 comenta: No trabalho de parto eu tava comendo, ainda cheguei a almoçar. Já Prazeres 17 relata que: Comer não, eu fiquei vomitando e bebendo muita água. $\mathrm{O}$ MS preconiza a ingestão de líquidos, de preferência, soluções isotônicas ao invés de somente água, e uma dieta leve. ${ }^{13}$ 
No total de partos, 12 foram descritos sem nenhuma intervenção; três mulheres passaram pela ruptura artificial da membrana amniótica, uma utilizou infusão de ocitocina e duas receberam ambas as intervenções, empregadas para o que se denomina 'manejo ativo', com o intuito de acelerar o trabalho de parto. Como demonstrado nos trechos das entrevistas abaixo:

Porque quando eu entrei tava com cinco (centímetros de dilatação), só que o problema foi que depois minhas contrações passou, num vinha mais. Tive que tomar soro pra ver se conseguia voltar as contração, ai acabou estourando minha bolsa e foi quando consegui ter (Prazeres 7).

Eles perguntaram se eu queria (amniotomia), ai eu disse que queria para agilizar (Prazeres 2).

Uma revisão sistemática apontou redução modesta do número de cesarianas quando o manejo ativo do trabalho de parto é praticado, em comparação com o manejo expectante. Contudo, os benefícios desta pequena redução devem ser ponderados contra os riscos de intervenções em mulheres de risco habitual. ${ }^{17}$

\section{Humanização do nascimento e cuidados pós-parto}

As Diretrizes Nacionais de Assistência ao Parto Normal, chamam atenção para o período imediatamente após o nascimento como um momento bastante sensível, e que a assistência deve ser no sentido de minimizar a separação entre mãe e filho. ${ }^{13}$ Dentre os relatos, percebe-se o cumprimento da 'hora dourada' através, do contato pele-a-pele entre mãe e bebê imediatamente após o nascimento por pelo menos uma hora; clampeamento tardio do cordão umbilical; incentivo a mãe para reconhecer quando o bebê já está pronto para a amamentação, oferecendo ajuda, se necessário $^{16}$ :

Botaram logo ela em contato comigo e já mandaram eu dar de mamar também (Prazeres 7).

Ela mamou quase uma hora completa, isso acho que é único assim, coisa que você não ver em outros tipos de parto né. [...] A gente só cortou o cordão depois que a placenta saiu, inclusive foi meи marido que cortou. Então a gente esperou a placenta sair depois cortou o cordão umbilical, perguntaram se eu queria fazer alguma coisa com o cordão, se eu queira fazer alguma coisa com a placenta (Prazeres 12).

Observou-se também a valorização da equipe para os aspectos subjetivos envolvidos no momento, como a oportunidade do acompanhante realizar o corte do cordão umbilical. Tal qual, para algumas mulheres o contato com a placenta emergiu diversos significados, superando a construção biomédica de resíduo clínico. Ainda que não seja uma prática uniforme em todos os plantões, o carimbo da placenta (feito como uma estampa em uma tela) mostrou-se um poderoso símbolo de maternidade, nascimento e vida.

$V i$, peguei minha placenta, a placenta foi pra cima de mim, tirei foto, foi carimbada, tá ali meu carimbinho da placenta dela (Prazeres 1). 
Eu pedi pra pintar ela (placenta) pra guardar, mas demorou tanto, demorou, demorou e terminou não fazendo nada (Prazeres 5).

Nesse cenário, a única intervenção que marcou o pós-parto imediato de sete das 11 mulheres que tiveram laceração perineal, foi a sutura para reparação. $\mathrm{O}$ CPN valoriza a taxa zero de episiotomia, uma vez que não há evidências que corroborem a necessidade do seu uso rotineiro ou liberal ${ }^{16}$, mas a partir dos relatos pressupõe-se um percentual significativo de lacerações espontâneas. A Cochrane Data base of Systematic Reviews, realizou uma revisão para avaliar o efeito das técnicas perineais durante o segundo estágio do trabalho de parto sobre a incidência de trauma perineal, sugerindo que compressas quentes e massagens podem reduzir as lesões de terceiro e quarto graus, mas não foi claro o impacto dessas técnicas em outros desfechos. ${ }^{18}$ Outra revisão concluiu que não há evidências suficientes para avaliar os benefícios e os riscos entre suturar e não suturar lacerações de segundo grau. ${ }^{19}$ Mas a não sutura pode melhorar a satisfação das mulheres, visto que foi relatada como um procedimento doloroso e incomodo:

Ela foi ver se precisava de ponto, aí ela foi passou anestesia e incomodou, tinha que dá de instante em instante anestesia porque tava doendo (Prazeres 5). Teve laceração, acho que é assim que chama. Aí me incomodou muito [...] eu tava já sem força pra nada (Prazeres 4).

\section{A satisfação com a assistência e o reconhecimento das enfermeiras}

A satisfação com a assistência recebida foi o sentimento que predominou entre as participantes desta pesquisa, no conjunto de fatores técnicos e humanos envolvidos. Destacou-se a relação interpessoal como um fator importante para a promoção da humanização, pois, as mulheres se sentiram acolhidas e amparadas, resultando em maior confiança e segurança no trabalho de parto e parto. ${ }^{12}$ Segue alguns exemplos:

Eu sinto que ainda existe muita violência obstétrica por aí [...] eu já escutei muito relato. Mas aqui não, então eu queria que todas as mulheres pudessem passar pela mesma experiência que eu tive, porque foi ótimo (Prazeres 1).

Quando a minha acompanhante ela teve que descer pra almoçar, ela (enfermeira) veio ficou comigo conversando no quarto, na hora que eu sentia a dor fazia massagem. Então foi bom, passou confiança, eu gostei dessa parte, foi diferente (Prazeres 8).

Maravilhoso, só gratidão mesmo, tem o que falar das meninas não. Realmente ajuda, faz massagem, conversa e eu tô pra ver um lugar aonde tenha pessoas assim que trabalhe com amor (Prazeres 16).

Os discursos sugerem uma relação de vínculo entre usuária-profissional, mas um fator confundidor foi a imprecisão quanto ao nome e a categoria profissional da responsável pelo parto. Uma mulher não tinha lembrança sobre a identificação das profissionais, outra afirmou que as mesmas não se apresentaram, três referiram apresentação somente do nome e 13 
afirmaram ser informadas do nome e categorial da profissional - entre essas últimas, a maioria não recordava os dados da apresentação. Sendo recorrente na fala das participantes, a identificação da responsável pela assistência ao parto como médica, mesmo a equipe constituindo-se exclusivamente por enfermeiras obstetras e técnicas de enfermagem:

(Você sabe qual é a profissão de quem lhe atendeu?) Enfermeira, acho que chefe também, doutora também (Prazeres 14).

Eu não lembro o nome, mas era duas estagiárias e duas médicas (Prazeres 5).

Todas que entrou se apresentou, conversou. Mas a pessoa com dor não tá prestando muita atenção não (Prazeres 8).

Mesmo com apresentação desde o nome, sua inserção na equipe e o que compete a ela executar, revela-se o não reconhecimento da enfermagem por parte das mulheres entrevistadas. Os desafios emergem através de uma constelação de poderes, mostrando que a tarefa é complexa. Trata-se de um movimento tenso, de investir contra a ordem instituída, na direção de um modelo centrado na mulher e desmedicalizado. ${ }^{20}$

\section{CONCLUSÕES}

Em suma, o CPN foi avaliado positivamente por meio dos relatos maternos, confirmando a premissa de que a ambiência e as boas práticas de cuidado interferem na qualidade da assistência ao parto. $\mathrm{O}$ atendimento da enfermeira obstetra destacou-se pelo suporte e acompanhamento contínuo no trabalho de parto e parto, com uso de tecnologias não invasivas e respeito à mulher. Espera-se visibilizar a importância dessa profissão para reconfiguração do cenário assistencial, através de uma atuação autônoma e qualificada. Nesse sentido, também é indispensável o fortalecimento do SUS e das políticas públicas de saúde materno-infantil, inclusive fomentando a construção de novos CPN.

O movimento pela humanização do parto e nascimento inclui diferentes atores, aqui resgatou-se o papel central da mulher nesse processo. A percepção das mulheres entrevistadas suscitou informações relevantes, que devem ser consideradas pelos profissionais de saúde, para melhoria na qualidade da assistência. Portanto, o cuidado mais efetivo é aquele voltado às necessidades das parturientes, orientado pelos direitos sexuais e reprodutivos, e baseado em evidências científicas.

Este estudo foi limitado à apenas um CPN que possui suas especificidades contextuais; porém, resultados similares podem ser encontrados em outros locais que sigam as diretrizes definidas pelo MS. Outra limitação foi a investigação dos significados atribuídos à assistência obstétrica apenas pelas puérperas, sem explorar a perspectiva dos demais atores 
envolvidos nesse processo, como os familiares e as enfermeiras. Ainda assim, este trabalho avança na construção de um conhecimento pouco explorado no cenário materno-infantil, destacando a contribuição da enfermagem obstétrica.

\section{REFERÊNCIAS}

1. Pimentel C, Rodrigues L, Müller E, Portella M. Autonomia, risco e sexualidade: a humanização do parto como possibilidade de redefinições descoloniais acerca da noção de sujeito. REALIS [Internet]. jan/jun 2014 [citado em $20 \mathrm{dez}$ 2021]; 4(1):166-85. Disponível em: https://periodicos.ufpe.br/revistas/realis/art icle/view/8813/8788

2. Rede Nacional Feminista de Saúde, Direitos Sexuais e Direitos Reprodutivos. Dossiê humanização do parto [Internet]. São Paulo: Rede Nacional Feminista de Saúde; 2002 [citado em 25 maio 2019]. 40 p. Disponível em: https://redesaude.org.br/wpcontent/uploads/2021/01/Dossie_Humaniz acao-do-parto.pdf

3. Ministério da Saúde (Brasil). Portaria ${ }^{\circ}$ 11, de 7 de janeiro de 2015. Redefine as diretrizes para implantação e habilitação de Centro de Parto Normal (CPN), no âmbito do Sistema Único de Saúde (SUS) para o atendimento à mulher e ao recém-nascido no momento do parto e do nascimento, em conformidade com o Componente PARTO E NASCIMENTO da Rede Cegonha, e dispõe sobre os respectivos incentivos financeiros de investimento, custeio e custeio mensal [Internet]. Brasília, DF: Ministério da Saúde; 2015 [citado em 20 dez 2021]. Disponível em:

https://bvsms.saude.gov.br/bvs/saudelegis/ gm/2015/prt0011_07_01_2015.html

4. Garcia LV, Teles JM, Bonilha ALL. O centro de parto normal e sua contribuição para atenção obstétrica e neonatal no Brasil. Revista Eletrônica Acervo Saúde
[Internet]. 2017 [citado em $20 \mathrm{dez}$ 2021]; (Supl 7):356-63. Disponível em:

https://acervomais.com.br/index.php/saude /article/view/8278/4995

5. Santana AT, Felzemburgh RDM, Couto TM, Pereira LP. Atuação de enfermeiras residentes em obstetrícia na assistência ao parto. Rev Bras Saúde Mater Infant. [Internet]. jan/mar 2019 [citado em $20 \mathrm{dez}$ 2021]; 19(1):135-44. Disponível em: https://www.scielo.br/j/rbsmi/a/btdZrZ4bX TQpcj6qnyLDxSm/?format=pdf\&lang=en 6. Minayo MCS, organizadora. Pesquisa social: teoria, método e criatividade. Petrópolis: Editora Vozes; 2016 [citado em 20 dez 2021]. 67 p. (Série Manuais Acadêmicos)

7. Nascimento LCN, Souza TV, Oliveira ICS, Moraes JRMM, Aguiar RCB, Silva LF. Saturação teórica em pesquisa qualitativa: relato de experiência na entrevista com escolares. Rev Bras Enferm. [Internet]. 2018 [citado em 25 jun 2019]; 71(1):228-33. Disponível em: https://www.scielo.br/pdf/reben/v71n1/pt_ 0034-7167-reben-71-01-0228.pdf

8. Bardin L. Análise de conteúdo. São Paulo: Edições 70; 2016.

9. Conselho Nacional de Saúde (Brasil). Resolução No 466, de 12 de dezembro de 2012. Trata de pesquisas em seres humanos e atualiza a Resolução 196 [Internet]. Brasília, DF: CNS; 2013 [citado em 20 dez 2021]. Disponível em: https://bvsms.saude.gov.br/bvs/saudelegis/ cns/2013/res0466_12_12_2012.html 10. Dias PF, Miranda TPS, Santos RP, Paula EM, Bem MMS, Mendes MA. Formação do conceito ambiência para trabalho de parto e parto normal institucionalizado. Rev Bras Enferm. [Internet]. dez 2019 [citado em $20 \mathrm{dez}$ 2021]; 72 (Supl 3):348-59. Disponível em: https://www.scielo.br/j/reben/a/3zktZpGzn sL4zTMnsLbNbxF/?format=pdf\&lang=en 11. Alves TTM, Paixão GPN, Fraga CDS, Lírio JGS, Oliveira FA. Atuação da enfermeira obstetra no desenrolar do trabalho de parto e parto. Rev Enferm Atenção Saúde [Internet]. jan/jul 2018 
[citado em 25 jun 2019]; 7(1):41-50.

Disponível em:

http://seer.uftm.edu.br/revistaeletronica/ind ex.php/enfer/article/view/2282/pdf

12. Borja TJ, Freitas WMF, Santos LS, Nascimento BGS, Lima DRA, Silva JCMC. O cuidado prestado por doulas em uma maternidade pública: o olhar das puérperas. Rev Enferm Cent.-Oeste Min. [Internet]. 2018 [citado em $20 \mathrm{dez}$ 2021]; 8:e2878. Disponível em:

http://seer.ufsj.edu.br/index.php/recom/arti cle/view/2878/2046

13. Ministério da Saúde (Brasil), Secretaria de Ciência, Tecnologia e Insumos

Estratégicos, Departamento de Gestão e Incorporação de Tecnologias em Saúde. Diretrizes nacionais de assistência ao parto normal: versão resumida [Internet].

Brasília: Ministério da Saúde; 2017 [citado em 20 dez 2021]. 51 p. Disponível em: https://bvsms.saude.gov.br/bvs/publicacoes /diretrizes_nacionais_assistencia_parto_no rmal.pdf

14. Souza SR, Leão IMM, Almeida LA. A gestante no pré-parto: a fisioterapia traz benefícios? Scire Salutis [Internet]. ago 2018 [citado em 21 dez 2021]; 8(2): 10414. Disponível em: https://sustenere.co/index.php/sciresalutis/a rticle/view/CBPC2236-

9600.2018.002.0011/1283

15. Ministério da Saúde (Brasil).

Resolução Nº 36, de 03 de junho de 2008. Dispõe sobre Regulamento Técnico para Funcionamento dos Serviços de Atenção Obstétrica e Neonatal [Internet]. Diário Oficial da União, Brasília, DF, 3 jun 2008 [citado em $21 \mathrm{dez}$ 2021]. Disponível em: https://bvsms.saude.gov.br/bvs/saudelegis/ anvisa/2008/res0036_03_06_2008_rep.htm 1

16. World Health Organization. WHO recommendations: intrapartum care for a positive childbirth experience. Geneva: WHO; 2018. 195 p. Disponível em: http://apps.who.int/iris/bitstream/handle/10 665/260178/9789241550215eng.pdf;jsessionid $=668165211489 \mathrm{BAB} 9 \mathrm{E}$ 7D347CB903C1885? sequence $=1$ 17. Wei S, Wo BL, Qi HP, Xu H, Luo ZC, Roy C, et al. Early amniotomy and early oxytocin for prevention of, or therapy for, delay in first stage spontaneous labour compared with routine care. Cochrane Database Syst Rev. [Internet]. 2013 Aug [citado em 03 jan 2021]; 7(8):CD006794. doi: 10.1002/14651858.CD006794.pub4 18. Aasheim V, Nilsen A, Reinar L, Lukasse M. Perineal techniques during the second stage of labour for reducing perineal trauma. Cochrane Database Syst Rev. [Internet]. 2017 Jun [citado em 03 jan 2021]; 6(6):CD006672. doi: 10.1002/14651858.CD006672.pub3 19. Dudley LM, Kettle C, Ismail KMK. Secondary suturing compared to nonsuturing for broken down perineal wounds following childbirth. Cochrane Database Syst Rev. [Internet]. 2013 Sep [citado em 03 jan 2021]; (9):CD008977. doi: 10.1002/14651858.CD008977.pub2 20. Gomes ML, Moura MAV, Souza IEO. Obstetrical practice by nurses in institutional childbirth: a possibility for emancipatory know ledge. Texto \& Contexto Enferm. [Internet]. $2013 \mathrm{Jul} / \mathrm{Set}$ [citado em $21 \mathrm{dez}$ 2021]; 22(3):763-71. Disponível em: https://www.scielo.br/j/tce/a/BntrD3VQwc B6bYG5xrDJz6q/?lang=en\&format=pdf

RECEBIDO: 07/06/2020

APROVADO: $11 / 03 / 2021$

PUBLICADO: dez/2021 